

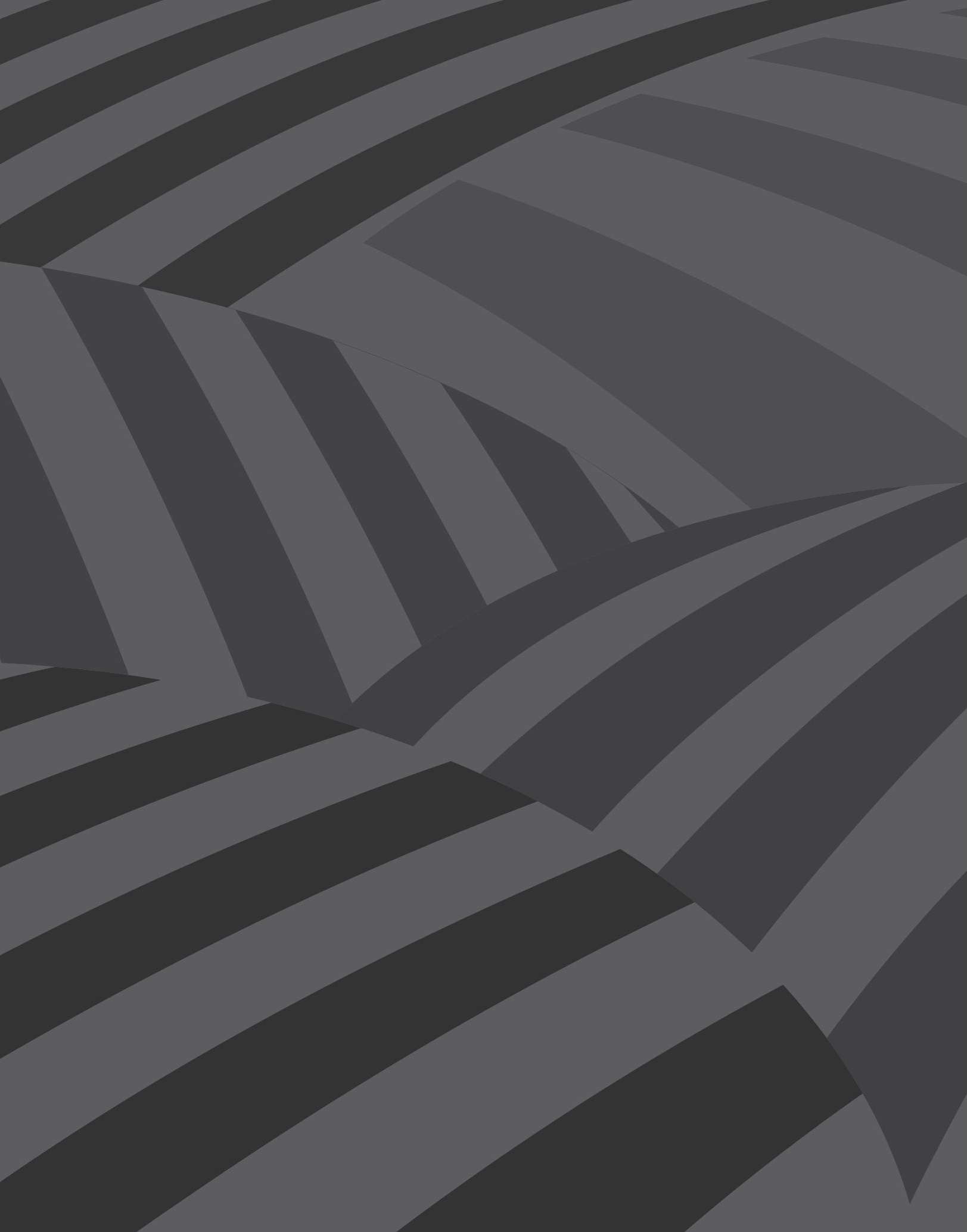




\title{
Memorias del conflicto armado en el corregimiento sur-oriental de Fusagasugá (1990-2003)
}

\author{
Por David Fernando Tinjacá Gómez, Wilmer Alexander Usaquén Cobos*
}

Resumen: Colombia ha sufrido por más de cinco décadas un conflicto armado interno que ha generado profundos impactos en la población civil, en particular para los campesinos. Históricamente la región del Sumapaz ha sido uno de los epicentros de esta confrontación que, durante el periodo comprendido entre 1990-2003, adquirió características particulares debido a la expansión de los actores armados enfrentados. En este artículo se analiza cómo se desarrolló ese enfrentamiento en el corregimiento suroriental de Fusagasugá; con este objetivo, se hace énfasis en los relatos de las personas que vivieron los hechos, para así proyectar el problema de la memoria histórica en la región campesina del Sumapaz. Lo anterior permite observar las experiencias de los sujetos frente al fenómeno de la violencia y cómo son recordados estos, de cara a un periodo de posacuerdo, momento en el que se hace necesario conocer y dar sentido a las memorias de quienes sufrieron los mayores impactos de nuestra guerra.

Palabras clave: conflicto armado, FARC, memorias, Sumapaz.

\section{Armed Conflict Memories in the Southeastern Corregimiento of Fusagasugá (1990-2003)}

Abstract: Colombia has suffered an armed conflict for more than five decades with deep impacts on civilians, particularly the peasantry. Historically, the Sumapaz region has been one of the epicenters of this confrontation, with very particular features from 1990 to 2003, due to the expansion of armed actors. This paper analyzes how the confrontation took place in the southeastern corregimiento of Fusagasugá, from the perspective of the people who experienced it firsthand, in order to contribute to the historical memory of the peasant region of Sumapaz. This exercise allows to observe the divergent interpretations that exist about the same phenomenon of violence, which is useful facing the current period of post agreement, where it is necessary to know and make sense of the memories of those who suffered the greatest impacts of our war.

Keywords: Armed conflict, FARC, memories, Sumapaz.

* Licenciados en Educación Básica con énfasis en Ciencias Sociales de la Universidad de Cundinamarca, sede Fusagasugá. Correos electrónicos: dft56@outlook. com,wilmer.usaquen@hotmail.com 
Cómo citar este artículo: Tinjacá Gómez, David Fernando y Usaquén Cobos, Wilmer Alexander (2019). Memorias del conflicto armado en el corregimiento sur-oriental de Fusagasugá (1990-2003). Revista Controversia, 213, 297-338.

Fecha de recepción: 27 de marzo de 2019

Fecha de aprobación: 18 de junio de 2019

\section{Introducción}

El conflicto armado interno en Colombia como fenómeno social, político y militar de larga duración ha afectado el desarrollo de la historia reciente de nuestro país, ya que ha estado íntimamente ligado a la vida de las comunidades rurales, en razón a una serie de contradicciones históricas - como la posesión de la tierra- que pusieron en el centro de la confrontación al campo colombiano. La región del Sumapaz ha sido históricamente asociada a las luchas por la tierra de las comunidades campesinas, por lo cual ha presentado una convergencia entre territorios rurales y violencia durante varias décadas.

Un antecedente remoto de este proceso se ubica en las luchas por la posesión y titulación de la tierra emprendida contra los terratenientes por colonos y arrendatarios en los años veinte y treinta del siglo xx. Esta movilización campesina estuvo influida por agrupaciones como la Unión Nacional de Izquierda Revolucionaria (UNIR) y logró una respuesta del Gobierno por medio de la colonización dirigida y la parcelación de haciendas; además, cimentó una robusta base política liberal y gaitanista. Fue ese carácter el que definiría al Sumapaz durante la Violencia del medio siglo, cuando después del fin de la República Liberal y del ascenso de Mariano Ospina a la presidencia, la disputa de los partidos tradicionales fue derivando en una violencia política que alcanzó su punto de quiebre con el magnicidio de Jorge Eliécer Gaitán en 1948.

Pronto la violenta oleada de masacres y persecuciones llegó al flanco sur del Sumapaz y provocó la formación de grupos de autodefen- 
sa campesina en El Palmar, Guanacas y El Roble (Marulanda, 1991, pp. 74-78). En este periodo pueden distinguirse tres fases principales. La primera se caracteriza por el proceso de resistencia campesina que fue centralizado políticamente por Juan de la Cruz Varela -afiliado durante la guerra al Partido Comunista de Colombia (PCC) - y que culminó con la entrega de armas en Cabrera en 1953, tras el golpe militar de Rojas. Una segunda fase se presentó desde fines de 1954, cuando afloró el discurso anticomunista del gobierno militar, lo que produjo la ilegalización del PCC y la represión hacia las zonas del Sumapaz consideradas como bastión rojo (Londoño, 2014, pp. 540-559). El pacto bipartidista de 1957 como acuerdo político entre élites liberales y conservadoras abrió la tercera fase cuando el movimiento guerrillero se acogió a la paz que ofrecían los partidos, pese a la presión latifundista por la tierra y a la guerra contra los limpios, exguerrilleros liberales no «contaminados» de comunismo.

Ese proceso de pacificación fue análogo en otras zonas de autodefensa campesina como Marquetalia, Guayabero o el Pato, etiquetadas por el gobierno como «Repúblicas independientes», donde, una década después, los movimientos organizados por el PCC retomaron las armas en un contexto de efervescencia revolucionaria y represión contra los focos de «comunismo». La excepción fue Sumapaz, donde la táctica fue la resistencia civil: dentro de esa lógica se mezcló la participación electoral con el Movimiento Revolucionario Liberal, el empleo de la prensa y el envío de comisiones a la capital.

En todo caso, la campaña contra las autodefensas campesinas y el «desmantelamiento» de las llamadas Repúblicas independientes entre 1964 y 1965 condujeron a la unificación de esos grupos y al surgimiento de las Fuerzas Armadas Revolucionarias de Colombia (FARC), cuyos principales bastiones se localizaron sobre el piedemonte de la Cordillera oriental en los antiguos territorios de El Pato, Guayabero, Alto Ariari y el Duda, colonizados por población ligada a los movimientos agrarios (Aguilera, 2013. p. 63). En ese sentido, para González (1992), es 
claro que «sobre los anteriores escenarios de «la Violencia», se fueron localizando los actores de la violencia contemporánea» (p. 13). El Sumapaz no sería la excepción.

Pese a esos antecedentes, el desarrollo reciente del conflicto en la región estuvo asociado de forma esencial a la VII Conferencia del Secretariado, celebrada en abril de 1982 (Pecaut, 2008, pp. 141-157). Esa reunión marcó una ruptura en el desarrollo del conflicto: las FARC abandonaron su posición como reserva estratégica del Pcc y se plantean la toma del poder por las armas mediante la construcción de un «Ejército del pueblo» cuyo eje de despliegue estratégico se posicionaría sobre la Cordillera oriental (donde está el Sumapaz), vital por la ubicación de la capital en esta (Pizarro, 2011, pp. 179-197). Dicho plan estratégico se vio limitado en la década de 1980, gracias a los diálogos de paz de La Uribe; pero la crisis a causa de la guerra sucia contra los militantes políticos de izquierda y la toma de la Casa Verde el 9 de diciembre de 1990 implicaron un cambio en las condiciones del conflicto armado, pues marcaron el inicio de una fase en que la acción de la guerrilla se desplazó del ámbito político al cumplimiento de su plan estratégico delineado en 1982. En este sentido, después de 1990, el conflicto armado adquiere unas condiciones particulares de expansión e intensidad que, para el caso del Sumapaz, abrirían un nuevo ciclo de enfrentamientos que concluiría con las ofensivas militares en 2003 y el Plan Patriota, cuando se produjo el repliegue de las estructuras guerrilleras de Cundinamarca (p. 279). Por esto, el artículo se centra en el periodo 1990-2003.

Ahora bien, debido a la forma en que se relacionaron esas dinámicas nacionales, regionales y locales en un territorio donde las comunidades tuvieron que desarrollar su vida en medio de la disputa de los actores armados, el corregimiento suroriental de Fusagasugá ofrece un escenario propicio sobre el cual plantearse el problema de la memoria del conflicto entre comunidades campesinas del Sumapaz. La memoria aparece como categoría emergente alrededor de los hechos traumáticos que han afectado a las sociedades que en procesos de tran- 
sición buscan responder a las víctimas, comprender el pasado y proyectarse luego hacia un futuro de no repetición. Adquiere valor en un lugar donde no hay documentos escritos y donde muchos testimonios de los campesinos que vivieron la guerra y sus alternativas permanecen ocultos: así se pueden empoderar aquellas voces silenciadas en el tiempo y se pueden palpar las disputas en torno a cómo se recuerda el conflicto. Porque, como sostiene Halbwachs (2004), si quienes recuerdan no son los grupos sociales sino los sujetos, estos no lo hacen sino en el marco social particular donde se desenvuelven.

El presente artículo hace parte de un trabajo de grado presentado en la Licenciatura en Educación Básica con énfasis en Ciencias Sociales de la Universidad de Cundinamarca. Para su elaboración, se consultaron diversos archivos municipales, fuentes escritas y fuentes orales recolectadas a partir de entrevistas no estructuradas que hicieron parte de un trabajo de campo practicado en las veredas del corregimiento suroriental de Fusagasugá durante el año 2018. Este buscaba recuperar las memorias de los habitantes rurales alrededor de su experiencia con el conflicto armado en la zona.

La temática está dividida en dos bloques. En el primero, se hizo un acercamiento histórico al problema del conflicto armado en las veredas, a través de la indagación por el contexto anterior a 1990 y la forma en que dicho fenómeno de violencia se vivió en la región hasta 2003, para lo cual se consideró la forma en que la población se relacionó con los actores armados. En la segunda parte, se analizó la manera en que se asume la memoria del conflicto armado entre la población del corregimiento suroriental, las divergencias que surgen en torno al recuerdo de ese pasado y, para cerrar el documento, la proyección de esas memorias hacia un futuro de paz.

\section{El corregimiento suroriental de Fusagasugá}

El corregimiento suroriental está ubicado en el municipio de Fusagasugá, capital de la provincia del Sumapaz en Cundinamarca. Conforma 
un triángulo desigual encajonado entre los municipios de Pasca y Arbeláez, por lo cual ofrece acceso a estas dos poblaciones con salida al páramo de Sumapaz y la localidad 20 del distrito. Circundado por los ríos Guavio y Batán, está compuesto por diez veredas, ubicadas a distintas altitudes, a las que se puede acceder desde la municipalidad por dos vías en regular estado de mantenimiento. Según datos de la Alcaldía Municipal de Fusagasugá (2012), 6976 personas viven allí. Se distinguen dos zonas: una parte llana denominada el Plan del Guavio y una zona alta y montañosa que enlaza con el vecino municipio de Pasca, donde están las veredas de El Carmen y Santa Lucía.

Como en el municipio en general, en dicho corregimiento predomina el minifundio y la mediana propiedad, pues el 91,86 \% del total de las fincas está representado por terrenos de menos de 5 hectáreas (pp. 12-13). La economía está orientada a la explotación agrícola con cultivos de clima frío y templado (frutas, hortalizas, café y plátano) y de bovinos de doble propósito, con coberturas de pasto en algunas veredas. Ahora, pese a la importancia del sector agrícola en la economía, el estado de las vías rurales está en "condiciones malas y regulares de transitabilidad», lo que eleva el costo de la producción. De acuerdo a las entrevistas efectuadas, muchos de los dueños de predios viven o trabajan en Fusagasugá. Por tanto, una de las condiciones socioeconómicas fundamentales es la existencia de una capa de población flotante, compuesta de arrendatarios y asalariados, y una elevada movilidad de la población rural. Con el marco de fondo de un mercado laboral informal y una limitada capacidad de ascenso social para los jóvenes, Fusagasugá, como capital provincial y polo de desarrollo local, ha ejercido de centro de recepción de la población joven de las veredas de ese sector. 


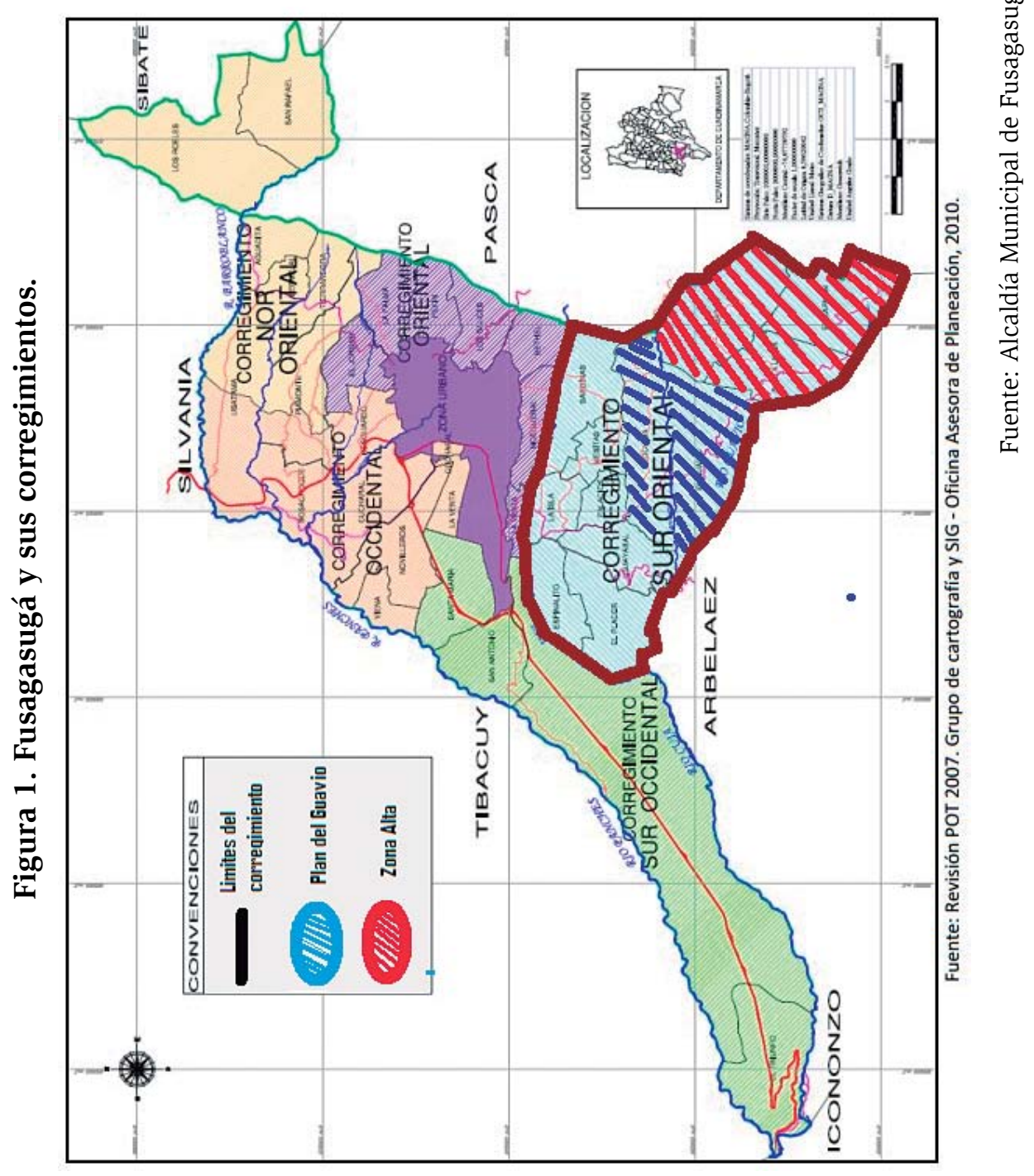




\section{Las veredas del sur y los conflictos agrarios}

Desde mediados del siglo xx, una serie de condiciones históricas señalan el carácter de la región como escenario de luchas agrarias. Para la década de los sesenta, en la parte alta de las veredas del sur (Santa Lucía, El Carmen y Batan), existían dos grandes haciendas llamadas El Carmen y La Selva, mientras que en el Plan del Guavio, sobre la parte media de la región, predominaban los pequeños y medianos propietarios. Una parte de la región estaba dedicada al cultivo de café como recuerdan los viejos líderes agrarios. Unas 50 familias provenientes de Pasca y Cabrera ligadas al movimiento agrario de Juan de La Cruz Varela, por entonces incluido en la pacificación del Frente Nacional, invadieron El Carmen e instalaron una serie de ranchos improvisados a fin de exigir la parcelación de las haciendas. Esto sucedió precisamente cuando la administración presidencial de Carlos Lleras Restrepo (19661970) impulsaba la implementación de la reforma agraria consagrada en la Ley $1 .^{a}$ de 1968. La respuesta consistió inicialmente en el despliegue de tropas pertenecientes a la Brigada de Institutos Militares (BIM), que por entonces tenía jurisdicción sobre Cundinamarca y amenazaba con un desalojo por la fuerza; pero dos años después, el gobierno central entró a negociar con los campesinos a través del Incora y la Caja Agraria, lo que derivó en la concesión de préstamos para la compra de terrenos y su parcelación. Entre las personas que se asentaron en Santa Lucía y El Carmen, estaban Adolfo Rodríguez, un militante comunista excombatiente de la Violencia, y Alfonso Mora, que luego sería líder veredal y concejal de Fusagasugá entre 1991 y 2000; ellos representaban las veredas del sur (Mora, 2018).

Este desarrollo de las luchas agrarias explica el nivel de movilización política que desarrollaron las organizaciones sociales presentes en el corregimiento durante al menos 30 años (de los setenta a los noventa). Entre ellos, jugó un papel destacado el Sindicato de las Veredas del Sur de Fusagasugá afiliado al Sindicato de Pequeños Agricultores de Cundinamarca (Sinpeagricun), el cual permitió a 
los campesinos organizarse autónomamente no solo de cara a la lucha por la tierra, sino también para dirigir algunas obras comunitarias de la mano del gobierno municipal, la Junta de Acción Comunal (JAC) y hasta el comité de cafeteros. Ese fue el caso particular de la carretera, las mejoras hechas en el colegio y las escuelas primarias o la extensión del acueducto y el tendido eléctrico, proyectos adelantados mediante el trabajo comunitario y la articulación con algunas entidades del gobierno, ya sea municipal o departamental, a lo largo de 30 años (de finales de los sesenta a mediados de los noventa).

\section{El conflicto armado entra en escena}

Pese a su pasado de luchas agrarias, hasta los años ochenta la presencia de las FARC se remitió a la parte alta del páramo (Cabrera y San Juan) y solo fue después de 1990 que se expandieron por toda la provincia, incluidas las veredas del corregimiento. De acuerdo a Pizarro (2011), ese gran despliegue guerrillero se hizo realidad a partir de diciembre de 1990 con el asalto a la sede del secretariado de las FARC en Casa Verde y la decisión consecuente de ejecutar el plan militar definido en la VII Conferencia de 1982, que señalaba a la Cordillera Oriental como su centro de despliegue estratégico. No obstante, también existía la necesidad, orientada por la guerra popular prolongada, de asegurar su presencia en zonas rurales durante un tiempo. Según Peña (1997), el despliegue se hizo, inicialmente, por parte de unidades del frente 22, que envió comisiones desde el noroccidente de Cundinamarca (Yacopí) y, más adelante, por parte de las estructuras instaladas en el Meta y la región del Duda (p. 91), lo cual derivó en la conformación de una serie de frentes, desde el 51 hasta el 55 en 1993. Particularmente, en la región de San Juan, con proyección hacia el municipio de Pasca, se instaló el frente 52 con control sobre las zonas altas del páramo.

Desde esas regiones altas que asumieron para mediados de la década de los noventa el carácter de zonas base, con presencia constante de los alzados en armas, las acciones de las FARC se fueron desplazando hacia las vertientes templadas de la Cordillera, para lo cual utilizaron una 
serie de corredores de movilidad que adquirieron singular importancia. Por estas vertientes se movían fuerzas para atacar o, en su defecto, replegarse tras efectuar acciones armadas, llevar intendencia o mover sus comisiones de finanzas (Beltrán, 2011, pp. 28-29). Por ejemplo, a través de Juan Viejo en Pasca, el Salitre en Arbeláez o por las veredas del sur en Fusagasugá, se llegaba a la capital provincial y a la vía panamericana, zona de alta inversión en renta por las fincas de descanso y recreo, actividades agrícolas y establecimientos comerciales.

En el corregimiento, esa implantación no llegó a hacerse en el vacío, según dijo Ernesto Cubillos, un militante de izquierda nacido en el Guavio, pues había una serie de condiciones sociales y políticas que facilitaron ese accionar. Para Alfonso Mora (2018), la presencia de las FARC en esa zona hacía parte de una tradición histórica que venía desde Juan de la Cruz Varela. Sin embargo, en los testimonios de personas que no conformaban ningún colectivo político, en la parte baja del corregimiento, se tiende a establecer un límite temporal entre el antes y el después de la aparición del actor armado como un evento que rompió de manera traumática la historia local. Ese fue el caso de la profesora rural Dora Baquero (2017), para quien la situación de «normalidad» dentro de la sociedad rural comenzó a verse afectada por la presencia de hombres extraños y los rumores sobre guerrilleros que terminaron por concretarse poco después.

En cualquier caso, la presencia de las FARC adquirió unas particularidades relacionadas con la historia previa de esta zona rural. Las veredas que comprendían el Plan del Guavio eran netamente un corredor de movilidad por donde se movían recursos para los subversivos, mientras que las zonas altas sí tuvieron una presencia más sostenida en el tiempo y el espacio de las FARC, dada la presencia de comunidades más organizadas políticamente y la cercanía con las veredas de Pasca y la parte alta de Arbeláez. A su vez, estas últimas se conectaban por trochas y caminos terciarios con Juan Viejo y la localidad 20, lugares donde había campamentos guerrilleros y un mayor control de estos sobre la gobernabilidad. En la zona alta, como afirma Alfonso Mora (2018), líder comunitario, la presencia más constante era de personal 
rebelde, de civil, es decir, milicianos más que guerrilleros en cuadrillas, quienes se movían en números reducidos. Así mismo, eran los encargados de dialogar con los líderes de la vereda, avisar sobre la presencia militar, cobrar vacunas o recoger las remesas y víveres que traían en carros y buses. Fue rara la ocasión en que las columnas armadas del Frente 52 hicieron presencia en gran número; solo en una ocasión específica se habló de 50 hombres que llegaron hasta el plan del Guavio, pues, en el resto de relatos recogidos en Santa Lucía y El Carmen, aparecen escuadras reducidas a diez o 20 militantes.

\section{La población en medio del fuego: la convivencia con las FARC}

Es claro que, para asegurar su presencia en un territorio, la insurgencia debía tejer unas relaciones con la población local que iban más allá de ejercer un simple control coercitivo. La presencia de cualquier actor armado, por tanto, no es algo unilateral y entra a enmarcarse en el espacio donde las comunidades desarrollan su vida, con lo cual se configura lo que Beltrán (2011) llama la triada Actor armado-Población-Territorio. Esta triada implica que los actores del conflicto, en el caso específico las FARC, otorguen a su relación con la población civil un carácter estratégico, pues, dentro de sus objetivos, la revolución solo se lograría con el apoyo de las clases populares, la utilización adicional de las características del territorio a su favor y el desarrollo de «un proceso de inserción en las lógicas gubernativas y de gestión de los asuntos públicos» (p. 19). Es por eso que, en el corregimiento, la convivencia de la población civil con el actor armado derivó en una relación compleja que se extendió durante un lapso apreciable y en múltiples espacios; esto dio lugar a una serie de grises que iban más allá del esquema simple de colaborar por miedo o no hacerlo. Aunque existía cierto temor por tener que convivir con unos hombres armados, no se puede considerar que la presencia de las FARC fuese vista como una simple expresión criminal: como actor armado, su repertorio de acciones era amplio y no se basaba solo en la coerción. En esa línea de análisis profundizada por Domínguez (2014), es necesario explicar que las FARC ejercieron su control a través del manejo de tres recursos. 


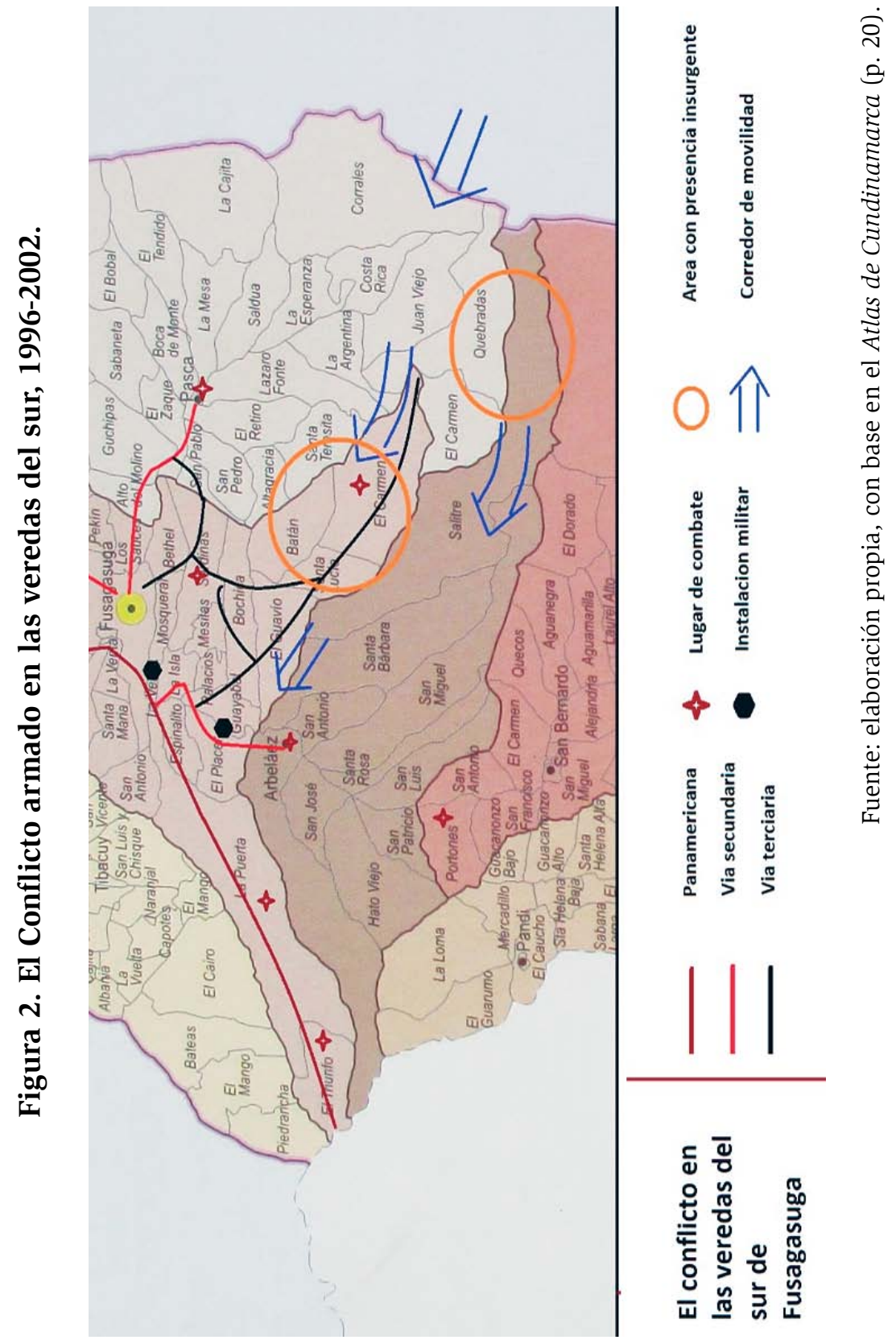


I) El control y/o cooptación de posiciones institucionales a través de la instrumentalización de las burocracias del poder público. Esta práctica podía situarse dentro del marco del clientelismo armado practicado por las FARC durante su periodo de expansión entre 1988 y 2003.

II) La capacidad de influir y movilizar a la población a través del control de medios, organizaciones o miembros notables de la comunidad. Por ejemplo, se recurría a las juntas de acción comunal para la ejecución de tareas de tipo comunitario que se esperaba beneficiaran a todos los campesinos.

III) Los medios coercitivos que refieren a las formas de ejercer presión por parte del actor armado, ya fuese de forma directa, con el uso de las armas, o indirecta, con restricciones y toques de queda que afectaban los medios tradicionales de sociabilidad en el campo. La anormalidad se impuso en el corregimiento para los jóvenes que salían a jugar en las canchas comunales o los varones adultos que se reunían en las tiendas a beber cerveza o jugar tejo.

El uso de las posiciones institucionales y la capacidad de movilizar a la población fueron empleadas por la guerrilla para desarrollar una labor que iba más allá de las simples acciones armadas y que buscaba brindar beneficios a las comunidades, aun cuando estos fueran utilizados para «ganarse el corazón de los campesinos». Así, el actor armado pasó a controlar en las veredas los órganos de poder local, con lo cual garantizaba el orden y la seguridad rural y se daba a conocer como agente garante, al usurpar esa función a los organismos del Estado, que, a juicio de muchos labriegos, no era cumplida con «eficacia». Las FARC llegaron hasta encargarse de la «agresividad de los borrachos en las fiestas» populares; incluso, intervinieron como mediadores en problemas de índole familiar, de pareja y hasta de cuota alimentaria, gracias a lo cual lograron resolver las más pequeñas disputas de la población civil.

En los diferentes testimonios, se revela cómo los campesinos, los líderes locales e incluso los profesores de la escuela rural local valoraban 
mucho algunos elementos aportados positivamente por la guerrilla. Tal es el caso del arreglo de las carreteras: no solo mejoraba la movilidad, sino que permitía sacar los productos agrícolas y ayudaba en la economía local. También, en el plano educativo, la docente Alcira Pachón (2018), quien enseñaba en una escuela rural, aseguró que la presencia guerrillera hizo que los requerimientos de las escuelas públicas fueran más ágilmente diligenciados por la Secretaría de Educación en Fusagasugá. Según ella, antes de la presencia de los subversivos no era raro que se presentaran muchas vacantes de docentes y que los puestos duraran desiertos varios meses; pero, después de que hicieran presencia en el sector «los muchachos» — referencia coloquial a los insurgentes-, nunca volvió a faltar un profesor para el colegio y se giraron «sagradamente» los recursos financieros. Aunque esa versión tiene su correlato.

La forma de ejercer control por parte de las FARC también frenó y limitó las actividades que los campesinos habían desarrollado con cierto grado de autonomía, a través del sindicato u otras agrupaciones. Según Adolfo Rodríguez, en cuanto la presencia de las FARC se hizo más fuerte y constante en las veredas del sur, la organización sindical de Sinpeagricun prácticamente perdió sus funciones, asumidas por el grupo armado que pasó a convocar las reuniones con el fin de apoyar las actividades de su estructura insurgente, sin darle voz propia a los campesinos o dejar espacio a su autonomía. En palabras de Rodríguez, eso significaba que «el que tiene las armas tiene el poder»: cuando él organizó una reunión con los campesinos de Santa Lucía y El Carmen para protestar contra los señalamientos que recibían ciertas personas por ser «informantes del ejército», recibió una sutil advertencia: «no se meta más».

A este factor se sumó la cuestión de las vacunas y la extorsión. El tema de las exigencias económicas de la insurgencia se explica en razón a que los frentes de las FARC no solo asumieron su papel como células de desarrollo político-militar, sino también como ente financiero, con la responsabilidad de construir una economía de guerra (Domínguez, 2014, pp. 119-124). La existencia de cultivos comerciales, sumada a la 
presencia de propietarios medianos con lotes de recreo, dieron pábulo a que también la delincuencia común aprovechara la presencia de grupos armados para «blanquear» sus acciones. Para combatir esas bandas que extorsionando usaban el rótulo de las FARC, el arma principal fueron los medios coercitivos. Numerosos abigeos y ladrones fueron notificados de que, si continuaban en su labor, serían objeto de castigo; cuando hicieron caso omiso de las advertencias, algunos fueron ajusticiados. Las FARC pasaron así a ser garantes del orden y la estabilidad local.

\section{El despliegue del Ejército}

Después de 1995, primero con la activación de las Fuerzas de Tarea y luego con el establecimiento del Batallón Sumapaz (Bisum), la presencia de las FF. MM. aumentó en la región general del Sumapaz con el fin de enfrentar la expansión de los frentes guerrilleros (Ejército Nacional, 2010). Particularmente, fue importante el hecho de que el Bisum instalara su puesto de mando sobre la carretera panamericana a pocos minutos del corregimiento, con el fin de controlar ese corredor vial y contrarrestar las acciones de las FARC.

Esa presencia puso a la población civil del corregimiento ante un nuevo actor, cuando el Ejército hizo presencia mediante sus patrullas de área. En principio no era común que chocara con los guerrilleros, porque estos no tenían unidades permanentes en la zona y, al decir de la profesora Dora y la comunidad en general, los dos bandos «se hacían los huevones»: cuando se presentaron combates, eran principalmente hostigamientos de unos cuantos minutos de duración y ambas fuerzas se retiraban tras algunos disparos y rompían contacto. Con todo, los militares no se limitaron al control de área y ensayaron otro tipo de acercamiento con la comunidad, con el fin de contrarrestar a los subversivos y alinear a la población civil a su favor, en un periodo álgido para enfrentar la expansión de los frentes de las FARC en la segunda mitad de la década de los noventa (Pecaut, 2008). De acuerdo con Alfonso Mora (2018), se llegó a proponer la conformación de un grupo 
de seguridad rural legal, denominado en ese momento Convivir, que se relaciona comúnmente con el proceso de expansión de las AUC y una doble estrategia contrainsurgente:

Una vez, era yo el vicepresidente de la Junta Comunal de Santa Lucía y llegó una compañía de treinta soldados y un teniente (...). Nos citaron en una reunión en la escuela de Santa Lucía a los campesinos para hablarnos de las Convivir (...): mire venimos a esto, es una orientación de tal cosa, esto de formar las Convivir. (...) Les dije: mire aquí hay conservadores, aquí hay liberales, aquí hay comunistas, aquí hay gente católica, hay gente evangélica, hay gente medio acomodadita y hay puros pobres, asalariados agrícolas, gente que emplea la mitad de su tiempo ganando el jornal y la mitad atendiendo su cementerita, pero todos nosotros nos estimamos (...) y no hubo las tales Convivir, la comunidad se resistió ante eso.

Es claro, como sostiene Beltrán (2011), que las comunidades no eran un simple objeto que se manipulaba a discreción de los actores armados, sino que también generaban sus propias respuestas frente a las iniciativas de estos.

A pesar de la tenue labor de sus inicios, pronto hubo una mayor conflictividad en las veredas del corregimiento y en general en el Sumapaz, conforme el conflicto escalaba en todo el país. En septiembre de 2000, se lanzó la Operación Aniquilador II que marcó el principio del esfuerzo estatal por asegurar militarmente la zona y cortar el avance guerrillero, en un momento en que estos se habían acercado a su centro de despliegue en la Cordillera Oriental. Durante 2001, en respuesta a esa avanzada, las estructuras de las FARC desataron una oleada de ataques que los llevó a tomarse la cabecera municipal de Arbeláez en junio de 2001; para dicho asalto, emplearon los corredores de movilidad que desde el páramo llevaban a las vertientes de la Cordillera, circunvecinas del corregimiento. Al mismo tiempo, allí se presentaban choques armados entre los guerrilleros y las Fuerzas Armadas. Uno de los combates que todos los entrevistados reseñaron ocurrió cerca de El Carmen, en la 
parte alta del corregimiento, cuando dos milicianos que actuaban como recolectores de la vacuna fueron sorprendidos y muertos por las tropas. Como consecuencia de estas acciones, el Bisum trasladó su puesto de mando a la vereda El Placer en la vía de Fusagasugá hacia Arbeláez en agosto de 2002, unos kilómetros más allá del desvío que lleva a las veredas del corregimiento suroriental por el corredor oriental (Ejército Nacional, 2010).

En esta fase es cuando se presenta el mayor número de homicidios en las veredas del sur. De acuerdo a los libros radicadores de las «Actas de inspección a cadáver» que reposan en las oficinas del Comité Técnico de Investigación (СтI) de la Fiscalía Seccional Fusagasugá, entre 1998 y 2001, se levantaron los cuerpos de catorce víctimas de homicidio en el corregimiento, todos civiles y varones, con edades entre los 17 y 60 años. De ese número, seis crímenes se registraron durante el 2000, lo que representaba un $15 \%$ del total sobre la estadística de 43 homicidios ocurridos ese año en Fusagasugá (Colombia, 2002, p. 10). Según Camilo Manjarrez, funcionario del CTI desde hace 25 años, esa cifra no incluye todos los casos ocurridos allí, pues sostiene que algunos cadáveres no eran levantados en el sitio de los hechos por cuestiones de orden público; además, los muertos en combate, fuesen guerrilleros o militares, eran evacuados hasta las instalaciones del Batallón Sumapaz, donde se efectuaba el procedimiento legal.

No obstante, además de la ofensiva militar, se produjo la incursión de las Autodefensas Unidas de Colombia (AUC), grupo paramilitar creado en abril de 1997, para combatir a los insurgentes con respaldo de diferentes sectores, élites locales y, en algunos casos, de la fuerza pública (Pecaut, 2008). Esta avanzada en la provincia quedó a cargo de las Autodefensas Campesinas del Casanare, que se instalaron principalmente en la vertiente occidental de la Cordillera sin entrar directamente al páramo (Valencia, 2010). Las amenazas que lanzaron sobre la población que supuestamente colaboraba con la subversión y en general sobre los líderes sociales se extendieron principalmente por algunas cabeceras 
municipales como Fusagasugá, Silvania o Icononzo. Las veredas del corregimiento no fueron ajenas a esa serie de acciones, pues, el 5 de febrero de 2001, las estructuras paramilitares amenazaron mediante un panfleto a los habitantes del corregimiento por «colaborar» con la guerrilla (Noche y Niebla, 2001, p. 62). Según Telmo Mora (2017), algunos grupos ligados a las AUC llegaron hasta el sector de Horizontes, casi que en la puerta de entrada al plan del Guavio. El 7 de febrero de 2003, parte de esas amenazas se cumplieron cuando un triple crimen ocurrió en la vereda Sardinas que queda en el sector oriental del corregimiento, a pocos minutos del casco urbano y sobre una de las vías que desde Fusagasugá llevan a Pasca. En un informe presentado por la Policía a la Alcaldía Municipal, se situaba el crimen como responsabilidad de las Autodefensas del Casanare (A. H. F., 2003, Secretaría de Gobierno).

Esa presencia de las AUC y la ofensiva del Estado fueron indicios de un proceso político-militar que señaló el fin de la presencia insurgente en buena parte de la provincia, acelerado tras la ruptura de las conversaciones de paz en el Caguán y, sobre todo, con el ascenso a la presidencia de Álvaro Uribe en agosto de 2002. El objetivo de la Política de Seguridad Democrática, pilar sobre el que centraba su acción Uribe, era asegurar el centro del país antes de emprender la ofensiva en la denominada retaguardia estratégica de las FARC y así quebrar el plan de guerra de esta organización alzada en armas (Ugarriza y Pabón, 2017, p. 293).

Para Pizarro (2011), con la gran ofensiva emprendida entre junio y diciembre de 2003, denominada por las FF. MM. como Operación Libertad I y que hizo parte del llamado Plan Patriota, se produjo un repliegue considerable de las estructuras guerrilleras de Cundinamarca en general (p. 279). Lo anterior tuvo sus consecuencias inmediatas en las veredas del corregimiento, donde la militarización de la zona marcó para algunos pobladores el fin de la presencia de los subversivos, con sus métodos de control coercitivos y exigencias económicas, pero también de sus labores comunitarias y la represión del abigeato. Por los relatos, parece evidente que no se produjeron grandes combates en la zona mientras 
se desarrolló esa operación, pues la presión militar obligó a que las FARC centraran primero su defensa en los antiguos territorios base y luego, ante la eventualidad de ser copados por la Brigada XIII y la Fudra, se replegaran hacia el Duda en el piedemonte del Meta (Bedoya, 2011, pp. 137-150). Ese fue el cierre de un periodo de presencia guerrillera que se había mantenido durante una década, pero su impacto en la memoria de la población campesina aún sigue vigente.

\section{Las memorias del conflicto armado en el corregimiento suroriental}

Como ya se señaló antes, en el desarrollo del conflicto armado la comunidad jugó un papel central no como un simple objeto manipulable, sino como actor, con unas acciones e iniciativas que a veces chocaban con los objetivos delineados por los armados. Desde una perspectiva más compleja, eso supone que no todos vivieron el conflicto de la misma manera y por tanto no lo recuerdan hoy de la misma forma, lo que genera divergencias en torno a lo que pasó, cómo pasó y por qué pasó.

Las memorias se comprenden, entonces, como una serie de narraciones estructuradas de situaciones específicas vividas por las personas. Ellos le darán un «sentido político y cultural compartido, depositario de una manera de recordar anclado en las subjetividades del presente, siempre construido dentro de un marco social» (Molano, 2009, p. 29). Estos marcos sociales, como señala Halbwachs (2004), son los ámbitos colectivos en los cuales los sujetos se encuentran inscritos (familia, lenguaje, momento histórico, etc.). La memoria, por tanto, depende del entorno social en que se encuentren las personas y es relativa a cada grupo, debido a que nadie recuerda lo mismo ni lo hace tampoco desde una única interpretación.

Es por eso que, desde los relatos de los habitantes del corregimiento en su doble rol de protagonistas y testigos de la violencia, es importante conocer las interpretaciones que guardan de sus experiencias con el 
conflicto armado y también las divergencias que emergen en las narraciones que los sujetos hacen de su pasado y del futuro que proyectan en él. Todo esto se relaciona de manera profunda con los marcos sociales en los que se hallan inscritos los individuos, cuestión de vital importancia, pues permitirá escuchar la voz y las subjetividades de los campesinos y la población rural en general.

\section{Impactos del conflicto: una mirada desde las memorias de los habitantes de las veredas del sur}

La recuperación de las memorias del conflicto armado da lugar a que este fenómeno sea interpretado a partir de las voces que históricamente han estado o han sido silenciadas y marginadas del ámbito político y social. Las memorias, en este sentido, viven en un continuo conflicto político frente a la historia oficial. Elizabeth Jelin (2002) señala que las memorias se establecen en constantes luchas, a través de procesos en los que algunos relatos logran desplazar a otros y se transforman en hegemónicos; por tanto:

Se trata de actores que luchan por el poder, que legitiman su posición en vínculos privilegiados con el pasado, afirmando su continuidad o su ruptura. En estos intentos, sin duda los agentes estatales tienen un papel y un peso central para establecer y elaborar la historia o memoria oficial. (p.40)

Como ya se mencionó, la presencia de cualquier actor armado no es unilateral y entra a enmarcarse en el espacio donde las comunidades desarrollan su vida. En el corregimiento suroriental, la convivencia del actor armado con la población civil fue una relación intrincada que se extendió durante un tiempo apreciable y en múltiples espacios. En ciertos sectores como los representados por las comunidades campesinas que llegaron con la invasión de las haciendas en los años sesenta, existía una línea histórica entre las luchas por la tierra, las guerrillas de Varela y la presencia fariana. Esto es claro en los relatos de los hermanos Mora, de Adolfo Rodríguez y Ernesto Cubillos, para quienes las 
FARC desarrollaron en la región una labor que iba más allá de las simples acciones armadas y que redundaban en beneficio de la población, aun en el caso de que fueran utilizadas como manera de ganarse a la comunidad y emplearla estratégicamente. Como dice Halbwachs (2004), la acción de retomar y reconstruir hechos del pasado siempre es social, pues tendrá en cuenta la relación existente entre el sujeto y los diversos grupos a los que está adscrito. Al revisar esas memorias, se evidencia una gran conciencia colectiva y política desde la población que ha estado ligada históricamente con las luchas campesinas del Sumapaz. Para muchos de ellos, la presencia de los insurgentes era algo que estaba naturalizado y legitimado. De acuerdo a Jairo Munarriz (2017), coordinador del colegio Guavio entre 1997 y 1999 —la única institución de educación pública en la zona-, entre los estudiantes de la escuela rural del Guavio la familiaridad era tan grande con los subversivos, que hasta llegaba a especularse sobre la participación abierta de ellos en las actividades de la organización alzada en armas. Al respecto comenta:

Alguna vez llegó Derechos Humanos de la Presidencia, que en ese tiempo era que manejaba la vaina... de... a cuestionarnos o directamente a decir que nosotros éramos auxiliadores ahí, zauxiliadores de qué? ¡Y sí que éramos auxiliadores! Nosotros, que nos comprueben, porque nosotros con ellos nada que ver... que permítame dos alumnos. Les dije yo: me da pena, podrá ser representante de Derechos Humanos, pero yo a mis alumnos no los prestó para nada... ¿Yo en esa vaina a cuenta de qué? ¡Me pudieran haber jodido! Dije no, yo no los presto ni me salen de aquí. ¿Qué les van a preguntar?, ¡qué les van a preguntar! Yo sabía a quiénes iban a llamar y por qué los estaban llamando... Yo sabía por qué los estaban llamando, y les dije, quieto ahí.

Es decir, si no existía la certeza, al menos sí había la idea generalizada de que las personas de la comunidad tenían una relación cercana con las FARC, a tal punto de que los profesores del colegio local recuerdan que los estudiantes empleaban algunas veces el chiste de recurrir a «los de arriba» para advertir jocosamente a sus compañeros desde una posición 
de poder, cuando disputaban sobre cualquier cuestión, ya fuera un juego o un problema en el aula. Eso demuestra cómo el actor armado había sido naturalizado y entrado a formar parte de la cotidianidad de la zona, aun de las mismas prácticas discursivas. Dice la profesora Alcira que esa relación llegó hasta el grado de que algunos de los subversivos, varones y jóvenes preferentemente, llegaban a recoger a algunos estudiantes a la salida de la jornada de clase en la sede principal; venían «enfusilados», a veces en moto, y trataban con los muchachos de $10 \mathrm{y}$ 11 como si fueran amigos cercanos.

Esa compenetración con las FARC llegaba en algunos casos al primer grado de consanguinidad:

Inclusive, yo aquí tuve un niño, un muchacho que fue alumno mío acá en la zona urbana, que fue hijo de un guerrillero con una alumna nuestra. Pues nosotros sí alguna vez vimos la relación, la vaina que tenían, pero nunca supe que tenían hijos. Cuando yo estaba en el salón de clase y llamé lista, vi los dos apellidos le pregunté que de quién era hijo. Me dijo, «no profe, yo soy hijo de fulano de tal». «iSu abuelo quién era?». «No, fulano de tal». Yo saqué conclusiones. (Munarriz, 2017)

Esa convivencia constante de la comunidad con la insurgencia, la exponía a señalamientos y hasta a cierto grado de estigmatización. Por eso, no fue extraño que los niños se vieran como un objetivo fácil en el afán de los militares por obtener fuentes de información en las veredas. Al saber que la mayoría eran de la zona y, más que nada, que eran considerados ingenuos frente a las intenciones y acciones de los actores en disputa, los soldados se acercaban a ellos con el fin de dialogar, pero, a la vez, de recabar cualquier dato sobre el enemigo. Como cuenta la profesora Dora Baquero (2017):

Yo tenía segundo y tercero de primaria en esa época, y llegaban los del Ejército y se ponían a hablar con los compañeritos y ahí mismo les decía (otro niño de la zona): «al salón», y les decía, «iqué hacen ahí plantados 
para que les averigüen la vida! ¡sí, como no son capaces de ir a buscar la guerrilla por allá en el monte y vienen a buscarla aquí!».

La acción de la delincuencia común también brindó elementos de análisis para observar cómo los pobladores percibían la presencia de los insurgentes. Por ejemplo, recuerda la profesora Dora Baquero, quien fue extorsionada por criminales comunes que utilizaban el rótulo de las FARC, que la guerrilla ejecutaba sus acciones de forma directa, sin intermediarios y anónimos, pero que algunos actores inescrupulosos usaban su nombre para escudar sus acciones y «meter terror». Este hecho implicaba que las FARC, como actor armado, fueran reconocidas por los pobladores con cierto grado de confianza y que estos confrontaran la versión oficial de la guerrilla como «grupo terrorista» casi criminal.

Lo mismo recuerda Ernesto Cubillos, quien decía que, aunque vestidos de civil, las comisiones de extorsión se presentaban personalmente en los predios a recibir la vacuna, lo que coincide con el resto de los testimonios. Estas dinámicas se explican porque las relaciones establecidas en la triada actor armado-población-territorio (Beltrán, 2011) no fueron unilaterales y no se redujeron a la simple coerción de los armados sobre los campesinos. Hubo ocasiones en que se valieron de ellos para obtener ciertas metas, como pasó con la docente Judith Quintana que vivía en el colegio de secundaria y cuyo comportamiento impedía la ejecución de un proyecto cafetero de la comunidad. Sobre esto dice el coordinador Munarriz (2017):

Ella vivía en el apartamento de ahí del colegio donde quedaba la rectoría: ese apartamento se necesitaba para empezar un proyecto que se había iniciado con el Comité de Cafeteros de producir el hongo para controlar la broca (...). La profesora le tocaba desocupar el apartamento y no quiso desocupar. Ella dice... «iA nosotros no nos cuesta nada!» (...) Ella dice que en la noche le llegaron unos personajes y le dijeron «tiene que irse porque no va amanecer...». Eso era lo que ella decía a nosotros. Nunca nos constó esa vaina. Después nos apareció otra vez, la misma semana, con la misma 
circunstancia. La verdad fue que terminó yéndose, terminó desocupándonos el apartamento y nosotros iniciamos el proyecto con la profesora Claudia, el proyecto para controlar la broca, que era un proyecto que se tenía con el Comité de Cafeteros, que fue uno de los proyectos buenos que se hizo allá en el colegio Guavio.

Esto último encaja con la visión de la comunidad que se vale de la guerrilla para mediar en un conflicto cuyo desenlace se esperaba que beneficiara a la comunidad o una parte de ella - la interesada en el proyecto cafetero- (Beltrán, 2011). Pero esta versión tiene su correlato de personas que rechazaban algunas de las formas de control impuestas, sobre las que ya se habló antes.

Personas de la región como Gladys Ovalle (2018) sostienen que las exigencias de las FARC fueron relativamente duras, derivadas de sus necesidades político-militares. Ella, que trabajaba en Fusagasugá, afirma que llegaron a exigirle 50 tarjetas de teléfono celular, en una época en que el trámite y los costos no eran tan expeditos, y que las extorsiones se dieron por parte de la guerrilla de manera generalizada, pues pedían a los agricultores un porcentaje del producto de toda cosecha que superara un millón de pesos. Con ese mismo dinero, según ella, el comandante de la zona, conocido como Pablo, iba a sentarse a tomar a las tiendas veredales. También afirma que, si los habitantes del sector no sostienen esta versión en público, es porque siguen viviendo en una zona donde aún hay gente que colaboró con la subversión y, por tanto, todavía temen a las represalias. Lo mismo sostiene Pedro Beltrán, hermano de la profesora María del Carmen, quien enseñaba y vivía en Santa Lucía: por cada cultivo se debía destinar una cifra para la insurgencia, así fueran medianos propietarios de tierra. Un número estimado lo brinda Stella Ausique, quien asevera que a su familia la guerrilla le hizo exigencias de dinero bastante altas que promediaban los $500 \mathrm{mil}$ pesos mensuales, cuota que tuvieron que pagar cuando regresaron a la vereda, luego de un periodo en que se desplazaron a Fusagasugá por temor a la confrontación entre los armados. 
Edilsa Flórez (2018), quien se desempeñó durante varios años como despachadora de la empresa Cootranspever, la única que prestaba servicio de transporte público en la zona, también apuntó que los mayores impactos surgieron alrededor de las exigencias que hacía la guerrilla en términos monetarios, amenazas y afectaciones que se tradujeron en miedo y daño psicológico cuando fue retenida por no cancelar una suma de dinero. Así narra este suceso:

Esa noche a mí me pusieron el revólver en la cabeza... Al otro día me dio un ataque de nervios, uno que no está acostumbrado a nada de eso, es horrible. El daño psicológico que le hacen a uno es grande, aunque no hubo muertes, pero sí un daño psicológico. Hubiera seguido ahí trabajando, ya estaría por pensionarme, vendí los cupos de las busetas, teníamos dos.

Esta situación no se limitó a Edilsa, pues sus compañeros también afrontaron las condiciones impuestas por el grupo guerrillero: estos les enviaron amenazas y hasta forzaron el desplazamiento de un conductor de la empresa que salió de la ciudad con su familia. En el caso de los propietarios medios de la región, ellos fueron los que terminaron en las cifras de población desplazada a causa de las exigencias económicas de las FARC. Gladys no vendió su propiedad como hicieron otros, pero tuvo que abandonar el predio hasta el 2003, cuando regresó con el repliegue de la subversión en el gobierno Uribe. Lo mismo sucedió con la familia Ausique.

A este escenario complejo se introdujeron más elementos después de que se produjo un mayor despliegue del Ejército en la zona. La presencia de más de un actor armado en las veredas supuso que la población quedara en medio de unos bandos enfrentados y claramente definidos, cuya respuesta derivó en estrategias de convivencia dominadas por el silencio. Para un sector de la población, los mayores impactos paradójicamente se produjeron en este lapso, lo que corrobora que la presencia insurgente no era catalizadora per se de la violencia armada y tenía efectivamente un repertorio de acciones más amplio que las balas 
(Beltrán, 2011). Sobre esto, es importante recordar que «el sentido del pasado sobre el que se está luchando es, en realidad, parte de la demanda de justicia en el presente» (Jelin, 2002, p. 43). Es decir, la memoria enunciada tiene el objetivo de legitimar ciertas interpretaciones de los sujetos (en este caso políticas) desde los recuerdos que han elaborado y, por tanto, las responsabilidades que adjudican a uno u otro grupo generalmente están relacionadas con su deseo de que la «verdad» sea contada o, al menos, de que la otra parte sea escuchada.

Respecto a ese periodo de disputa, recuerda la profesora Alcira Pachón (2018) que: «No era infrecuente que a cierta hora pasaron dos o tres guerrilleros que preguntaban por el paso de tropas del Ejército»; lo mismo sucedía con los soldados que indagaban a los habitantes del lugar sobre la presencia de los irregulares. La población, que quedaba en una posición delicada de equilibrista, respondía así: «pasaban por aquí, pero no sabemos adónde se fueron», «no sabemos» 0 «no vimos nada». Sobre la misma realidad, sostiene Julio Rodríguez (2017), un joven habitante de la parte alta del corregimiento: «tuve amigos que, en la familia, familiares fueron asesinados, fueron algunos... un conocido, un familiar por decirlo así se lo llevó la guerrilla en su momento y es la hora que uno no sabe nada de ellos, sí están vivos o no». Y agrega con vehemencia,

pero en muchas ocasiones ahí es donde está la confusión, porque podría ser la misma guerrilla y hasta el Ejército. Había momentos en que, si no lo amenazaba la guerrilla, lo amenazaba el Ejército, bien sea porque usted le colaboraba al Ejército o bien sea porque usted le colaboraba a la guerrilla, entonces usted siempre estaba en la mitad de los dos en el conflicto.

Lo anterior es ratificado por Iván Lombana (2018), quien vivía con su familia en la vereda Santa Lucía; sus padres eran propietarios de una tienda donde llegaban los lugareños a comprar víveres. Sostiene que el Ejército generó un impacto negativo para la población, a raíz principalmente de la estigmatización que ejercía sobre los civiles: 
El Ejército decía, «Ah es que ustedes le ayudan a la guerrilla con mercado, ustedes no sé qué», y, pues, sin embargo, el Ejército siempre llegaba y era a llevarse el mercado. Yo me acuerdo tanto que tres veces de las muchas que estuvieron nos revolcaron todas las cosas y se robaron... pues, porque eso se llama así... se nos robaron mercado, baterías, nos robaron muchas cosas que nosotros utilizábamos como la mercancía que vendíamos para que la gente comprara allá en la tienda. Por ejemplo, confundieron a mi primo con un miliciano. Entonces, mi primo esa vez no había llevado documentos y fue un dilema porque nosotros creíamos que lo iban a matar... Eso fue duro.

Los enfrentamientos armados de ese periodo también dejaron su secuela. Adolfo Rodríguez recuerda uno que lo sorprendió mientras jugaba tejo en una tienda de Santa Lucía: «estábamos todos ahí, cuando empezó la plomacera. Yo me tiré al piso, ahí (señalando) al pie de las canchas. La cosa pasó a los minutos, pero nos acabaron el juego. En eso quedó todo», concluye entre risas. Otro de esos combates lo menciona la señora Stella Ausique (2018), habitante de la vereda El Carmen, zona en la cual los enfrentamientos fueron más frecuentes. Según lo que describe, hubo varios episodios que ella define como traumáticos y marcaron su vida. Ese fue el caso no especificado de los asesinatos de algunos vecinos o, "por ejemplo, otra cosa que me impactó bastante fue la muerte de un soldado después de la activación de un petardo cerca acá a esta casa, en el cruce de arriba. Lo había puesto la guerrilla».

Hasta aquí, a partir de las narraciones recolectadas, se han conocido en general las dinámicas del conflicto en el corregimiento suroriental, sus significados y los mayores impactos sobre la población, en un ejercicio que conlleva la interpretación de las subjetividades surgidas en los hechos. Estas memorias divergentes se examinarán a continuación. 


\section{Memorias divergentes y expectativas de futuro}

La lucha por la memoria acarrea que los agentes sociales establezcan una oposición y pugnen contra aquellos que detentan el poder; en palabras de Jelin (2002), usan el pasado y colocan en la esfera pública otros sentidos del mismo. En este sentido, las memorias se pueden construir desde un campo conflictivo en diferentes ámbitos sociales y el corregimiento suroriental no es la excepción. Por ejemplo, durante las entrevistas, la mayoría de las personas mencionaron el histórico olvido estatal como uno de los factores que hizo posible la presencia de grupos armados en la zona, antes que hablar de «combinación de formas de lucha», terrorismo o narcotráfico. Al respecto, el líder comunal Alfonso Mora (2018) dice:

Aquí aún prevalece el abandono por parte de las administraciones, las carreteras en muy mal estado, las escuelas cuentan con malas infraestructuras, no hay espacios recreativos para los jóvenes, que ya ni les gusta trabajar y se vuelven flojos; tampoco en temas de salud, hasta hace poco el puesto de salud de la Trinidad.

Las exigencias, además, están ligadas básicamente a la oferta de condiciones dignas de vida, que logren que el campo sea atractivo para una generación de jóvenes, quienes, al no tener oportunidades educativas y laborales, migran hacia las ciudades. Estos discursos están presentes en las memorias de los habitantes del corregimiento, que tienen una interpretación crítica que confronta aquellas construidas por otros sectores. El conflicto armado, interpretado de esta manera, adquiere una dimensión político-social diversa y alternativa, como ha sido el reclamo de los marginados y excluidos frente a un relato hegemónico que reprodujo muchas veces una mirada unilateral sobre el tema: esta giraba en torno a una confrontación entre buenos y malos, pero sin reconocer la complejidad de una problemática que sigue latente. Adolfo Rodríguez (2018) recalca: «Acá siempre existió una organización de campesinos 
que han reclamado mejores cosas en términos de tierra y todo. No somos malos como muchas veces dice la gente».

Pero tampoco hay un relato homogéneo, pues las memorias de lo que pasó en el conflicto entran en un campo de divergencia, sobre todo, a partir de la posición política que toman las personas. Es de suma importancia observar en esos testimonios cómo surgen claramente unas diferencias en dos líneas principales, con voces que confrontan la versión «oficial» de los viejos líderes agrarios como Mora, de los jefes del sindicato como Rodríguez o de personas que militaban en partidos de izquierda como Cubillos. Son memorias de unas personas que vivían en el mismo sector y en la misma época, pero recuerdan diferente, están relacionadas con el marco social en que estaba inscrito cada sujeto. Por eso, en el caso de las veredas del corregimiento, la posición económica y el carácter o no de propietarios explican muchas de las divergencias en las memorias.

Hubo, en ese sentido, quienes en su momento simpatizaron con ideas de izquierda y apoyaron a la guerrilla, mientras que otras personas como Stella Ausique (2018) vieron como un hecho reprobable esa colaboración y resaltaron en cambio que las políticas del expresidente Uribe ayudaron a la normalización de las veredas. Stella, que rechaza la posición asumida por varios líderes actualmente en las JAC, dado su pasado de colaboración con los insurgentes y las «dobles intenciones», calificó de positiva la labor desempeñada por los militares - lo que se contrapone a las visiones reseñadas antes-y rechazó de plano a la guerrilla, aun cuando reconoce las condiciones de abandono estatal. Para ella, el Ejército cumplió su labor y liberó la región, mientras que la gente interesada, que sacaba réditos de los guerrilleros, era la que se oponía:

Hace poco vinieron algunos miembros del nuevo partido de la guerrilla y querían utilizar algunos espacios de la Junta para hacer su campaña. Yo me opuse, les dije que la Junta no era para eso, que lo hicieran por aparte, cuando estuvieron hicieron daño y ahora vuelven como si nada. 
En consonancia con lo anterior, Edilsa Flórez (2018) comenta que:

Una vez hicieron redada en Guavio, terrible, hicieron una redada, fue cuando Uribe Vélez estaba en la presidencia y cogieron a un poco de guerrilleros. Uribe regaba mucho ejército por las veredas y la presencia no más del ejército ahuyenta a la gente. Es que... si Uribe hubiera estado cuatro años más.

Para otras personas como Alfonso Mora y Adolfo Rodríguez, estas políticas no solucionaron las problemáticas históricas y más bien agudizaron el conflicto, debido a que se multiplicaron las confrontaciones armadas entre los dos bandos.

Otro elemento que es común al relato de casi todos los habitantes locales, y que permite observar claramente esas memorias divergentes sobre el conflicto, es el referente al tema del reclutamiento forzado. De algún modo, estaba presente el miedo de que reclutaran a los menores de edad, porque todos recogen la versión oficial pregonada por distintos medios de comunicación: «decían que los reclutaban que no sé qué, pero afortunadamente, que yo me acuerdo, en el colegio, nunca» (Beltrán, 2017). Pero, con todo y la generalización, más bien parece que los jóvenes no fueron reclutados a la fuerza, sino que había otros atractivos que explicaban su unión a las filas farianas, al menos en esta zona. Nadie se refirió a casos específicos y puntuales de enrolamientos por la fuerza. Dice Alfonso Mora (2018):

Eso (las armas) enamoraba mucho a los jóvenes. ¿Por qué? El guerrillero, por lo general, es preparado con la lengua para comprometerlo a usted, «mire, camine que no sé qué, camine que esto que lo otro», y, entre otras cosas, los muchachos veían la razón, porque había mucho muchacho con deseos de estudiar y no podía acá en las veredas. Cuando llegaron ellos, aquí no había colegio, no había puesto de salud. El colegio de Guavio estaría por ahí en construcción. 
Otros factores también parecían jugar su papel. Sobre ese tema, cuenta Edilsa Flórez (2018), dueña de una ruta de Cootraspever que prestaba servicio de transporte en la zona:

uno de esos un día vino y me saludó allí donde yo estaba. Era un chino que estudiaba en el colegio Guavio, decía que él era como informante y lo cogieron. Y vino y me dijo «iusted se acuerda de mí?», y yo me quedé mirándolo y le dije «sí, usted era el que lo habían cogido porque era guerrillero». Y dijo, «sí yo estaba preso, pero ya me soltaron». Era estudiante, era puro joven, vivían ahí en Guavio.

Agrega que ese era un joven al que su padrastro maltrataba constantemente y que, al buscar escape de su situación, terminó en las filas de la insurgencia.

En un escenario como el de la ruralidad colombiana, en el que la pobreza por nivel de ingreso era del orden del $74 \%$ a fines de los noventa (desde entonces ha disminuido hasta el $44 \%$ en 2014, según el DNP), el conflicto armado interno termino reforzando lo que la Unesco (2011) denominó una espiral mortífera: se creó un movimiento cíclico en el que se siguió reproduciendo la violencia por las consecuencias que esta venía teniendo sobre la economía, el tejido familia y la educación (p. 152). Si se sigue esa línea de análisis, se observa que, en el caso particular del corregimiento, las condiciones económicas precarias del agro colombiano y la falta de presencia del Estado en temas como salud o educación no fueron creadas propiamente por el conflicto armado o sus actores: las pudieron exacerbar, pero no fueron sus causantes, aun cuando sí fueron elementos que motivaron, por ejemplo, el ingreso de más miembros de la comunidad a la subversión. Por tanto, muchos campesinos, sobre todo jóvenes en edad de formación y en búsqueda de desarrollar su vida adulta, ante la carencia de perspectivas en el agro o el maltrato en su núcleo familiar, cedían a la propaganda rebelde. Esta encontraba terreno fértil en las condiciones socioeconómicas de la región, frente a las cuales la atracción que ejercen las armas y una 
posición de poder y prestigio adquirida por la pertenencia a un grupo armado ostentaba un peso indiscutible.

De esta manera, las memorias son entendidas desde la multiplicidad de interpretaciones relacionadas con los marcos sociales particulares (como la pertenencia a un colectivo sindical o la condición de propietario o no de la tierra), que conllevan diferentes vinculaciones con la experiencia pasada y buscan imponer y legitimar su accionar sobre otras (Jelin, 2002). Se percibe, igualmente, que en algunos aspectos estos tipos de interpretaciones se ligan a narrativas oficiales que aún permanecen en el imaginario social de muchas personas y que, a su vez, pueden generar huecos y fracturas en los relatos. La visión de algunos sujetos que califican a los insurgentes como terroristas, extorsionadores o facinerosos, adjetivos que reducen su acción y presencia a estos términos, es particular de ese proceso.

Por ejemplo, respecto al significado que tuvo el repliegue de la guerrilla para el corregimiento, las respuestas son múltiples desde las memorias. Telmo Mora sostiene que hubo bastantes contradicciones: unos percibían a las FARC como un actor positivo que aun hoy echan de menos, mientras que otros, que sufrieron sus métodos y exigencias, dicen sentirse más tranquilos. Al decir de Halbwachs (2004), estos recuerdos están cargados de significados, determinados por las relaciones existentes en la sociedad dentro de la cual se elabora dicha memoria. En los diferentes testimonios se revela cómo los campesinos, líderes locales e incluso profesores valoraban esa serie de elementos, en los cuales la guerrilla aportaba positivamente: la profesora Alcira y Cubillos señalaban, por ejemplo, que los subversivos definían cada tres meses un día para que la comunidad colaborara en el mantenimiento y limpieza de las cunetas en las vías de acceso al corregimiento, para lo cual movilizaban a las personas obligatoriamente mediante ciertos liderazgos locales. Sobre esto, Ivan Lombana (2018) dice: 
Allá se decía: bueno, la vereda Santa Lucía tiene que hacerle mantenimiento a la carretera porque los gobiernos municipales no tenían mucha responsabilidad frente a las vías terciarias, que por sí nunca la han tenido. Ya ahorita se han visto algunos avances, pero en ese momento se convocaban a las mingas, entonces las mingas de trabajo, para ir a hacer las cunetas, porque de pronto ya se venía el invierno, ese tipo de cosas. Tocaba trabajar y, si alguien no podía ir, tenía que pagarle a alguien.

Sobre el rol de las FARC como garantes del orden y la estabilidad local -y hasta protectores de la propiedad campesina - señala uno de los hermanos Mora (2017):

Desaparecieron algunos que iban por allá a soplar a la Policía y al Ejército. Desaparecieron unas bandas de ladrones de esos que aparecen entre los campesinos, porque no tienen tierra donde trabajar y desde chiquitos ven robar y comienzan a robar y se vuelven los grandes ladrones por la tenencia de la tierra y la desorganización de la economía agraria a los campesinos. Ellos tienen que robar, porque meten la mano. Cuando llegó la guerrilla, pusieron freno, se hacían reuniones con la gente y les advertían que el ladrón que se descubra acá, lo castigamos. Una cosa era que llegaban a la casa y le decían, «váyase porque usted es ladrón» y, si seguía insistiendo o molestando, lo sacaban, lo sacaban.

En la otra esquina, es considerable también el sector de la población que se sintió aliviada por la partida de las FARC, puesto que fue un actor que hizo pesadas y constantes exigencias, sobre todo económicas, a los sectores productivos de la región, lo que provocó el desplazamiento y una crisis en las unidades agrícolas (Mora, 2018). El mismo líder comunal, Adolfo Rodríguez (2018), lo reconocía: «no me gustó mucho de eso es porque mataron muchachos inocentes, porque decían que estaban participando al Ejército, a los paramilitares que no sé qué. Pero uno veía y conocía el personal y eso no era así. Pero como ellos mandaban». 
Hay que recalcar, por último, que estas memorias buscan ser ejemplarizantes, es decir, utilizan el pasado en clave del presente de manera que puedan aprovechar las lecciones del conflicto armado, las injusticias, los silencios, entre otras cosas, para producir sentidos y construir identidad, actuar sobre el presente y modificar el futuro, en favor de la imposibilidad del olvido en el ámbito individual y colectivo. Ante esa posibilidad de un futuro de paz sin violencia, Iván Lombana (2018) sostiene:

Yo creo que, claro... o sea, bajar los fusiles es una gran oportunidad para que la población deje de vivir una de las tantas problemáticas que se tiene y, sobre todo, la población rural. Pero yo creo que no es suficiente, o sea, más allá de la guerrilla, yo creo que la responsabilidad del abandono que tiene el Estado y los gobiernos de turno frente al cómo solucionar las problemáticas de las veredas del campo colombiano es una tarea pendiente.

En esta misma dirección, otras voces coinciden en que, para alcanzar una paz verdadera y lograr que no se repitan episodios de violencia como los que han padecido, se deben articular todo tipo de políticas a nivel social, cultural y educativo, que fortalezcan las áreas rurales. Solo así se puede proyectar un futuro con mejores horizontes, que para ellos aún es incierto: «esperamos que no se vuelvan a presentar situaciones como las que hemos vivido, aunque últimamente se ha presentado delincuencia, mucho robo y demás... Esperemos que algún día tengamos mejoras» (Ausique, 2018). A pesar de que la incertidumbre de un futuro mejor es lo que prevalece en las memorias de los habitantes de las veredas, sin duda ellos también asumen una responsabilidad social frente a esos retos, mediante una organización que históricamente los ha caracterizado como población rural. «Acá seguiremos trabajando para buscar solución a las cosas, es algo que siempre hemos hecho con ayuda de todos», concluye Adolfo Rodríguez (2018). 


\section{Conclusiones}

La expansión general de las FARC en los noventa tuvo varias caras en la provincia de Sumapaz: desde las zonas que asumieron el rol de bases hasta las que estaban en disputa o eran corredores de movilidad. Uno de esos corredores, que desde el páramo llevaba a las estribaciones templadas de la cordillera y la capital de la provincia, pasaba a través de las veredas del corregimiento suroriental de Fusagasugá, que, por condiciones históricas y posición geográfica entre los municipios de Pasca y Arbeláez, se transformó en un escenario de presencia guerrillera. Sin embargo, la acción de las FARC no se produjo en un territorio vacío o de una forma unilateral que obedeciera solo a su plan de la guerra popular prolongada, ya que una serie de condiciones sociales, políticas y económicas, explicadas por los desarrollos históricos particulares del corregimiento y sus comunidades, tendieron a limitar o facilitar el accionar de los insurgentes y, en la última fase, de la Fuerza pública. Para Beltrán (2011), la población civil no era una simple comparsa en la confrontación, pues «también construye estrategias (...) que implican aceptar, rechazar, abastecer o utilizar económicamente a un actor armado» (p. 33).

Eso explica por qué el desarrollo del conflicto no fue uniforme en todo el corregimiento: mientras la guerrilla demostraba una presencia mayor en lugares como El Carmen, en el Plan del Guavio, en cambio, su acción fue más esporádica y orientada al sostenimiento y empleo del corredor de movilidad que llevaba hasta Fusagasugá. Lo anterior tiene relación con el hecho de que las comunidades que habían luchado por la tierra en los años sesenta y tenían un mayor grado de conciencia política estaban asentadas precisamente en la parte alta. Por eso, la guerrilla fue vista allí como un actor con una presencia hasta algún punto beneficiosa, explicable por las problemáticas del agro colombiano, a la que muchos jóvenes de las veredas del sur se unieron por voluntad propia, atraídos por una serie de ventajas que brindaba la pertenencia al grupo armado. Sin embargo, otro sector de la población civil que no estaba ligado a ningún movimiento social o político debió guardar una 
posición de equilibrio, primero, ante las exigencias de la insurgencia y, después, frente a la disputa territorial con la intensificación de la presencia del Ejército a finales de los noventa.

El hecho de que no toda la población civil viviera de la misma manera el conflicto, al hallarse inscritos en distintos escenarios y marcos sociales (políticos, sociales o de militancia política), explica las memorias divergentes de los habitantes de las veredas del sur. Las memorias —que no son homogéneas sino múltiples, pues están en relación con los marcos sociales en los que estén inscritos los sujetos (Halbwachs, 2004) - adquieren, por tanto, un gran significado político y social y se orientan esencialmente en dos sentidos. Los campesinos más viejos y sus descendientes que viven en la parte alta del corregimiento anclan sus memorias en las luchas agrarias del Sumapaz y se sitúan como afectados por el abandono del Estado y por una violencia estructural que va más allá de la presencia de los insurgentes. Otros, que no estuvieron en las luchas agrarias y viven sobre todo en la parte media y baja (no exclusivamente), se presentan como sencillos habitantes de la Colombia rural, expuestos al fuego de todos los bandos en una zona de conflicto donde se era sospechoso porque sí y porque no, sin llegar a justificar tampoco la presencia de los insurgentes que se volvieron, para muchos, parte del problema y no de la solución. La realidad de nuestro conflicto está plasmada paradójicamente en esas memorias divergentes, muestra de la profunda grieta que divide a la sociedad colombiana y su entendimiento de lo que pasó.

Por último, hay que decir que, en ambos grupos, pese a sus divergencias, esas rememoraciones están ligadas a una memoria ejemplar antes que a una literal anclada a la rememoración ritual de lo doloroso (Jelin, 2002). Desde esas memorias surge la expectativa de un futuro mejor para los habitantes del corregimiento con la implementación de políticas rurales que atraviesen diferentes aspectos como la educación, la cultura, los deportes y la economía. De lo contrario, existe el temor y la certidumbre de que estas vuelvan a convertirse en zonas de disputa armada. 


\section{Bibliografía}

Aguilera, Mario (2013). Guerrilla y población civil. Trayectoria de las FARC 19492013. Bogotá: Imprenta Nacional.

AHF - Archivo Histórico de Fusagasugá. 2003. Caja secretaria de gobierno

Alcaldía Municipal de Fusagasugá (2012). Plan de desarrollo municipal 20122015. Recuperado de: http://cdim.esap.edu.co/BancoMedios/Documentos \% 20PDF/fusagasuga-pd-2012-2015.pdf

Archivo del Comité Técnico de Investigación (Сті) (1995-2003). Libros radicadores de "Actas de inspección a cadáver», tomos 1-12. Fusagasugá: Fiscalía General de la Nación, Seccional Fusagasugá.

Beltrán, Santos (2011). Actor armado, territorio y población. Las lógicas de la guerra irregular. En: FARC-EP. Flujos y reflujos, la guerra en las regiones. Bogotá: Universidad Nacional de Colombia.

Colombia. Vicepresidencia de la República (2002). Panorama actual de la región del Sumapaz. En: Colombia, conflicto armado, regiones, derechos humanos y DIH 1998-2002. Bogotá: Programa Presidencial de Derechos Humanos.

Domínguez, José (2014). Las FARC EP, de la guerra de guerrillas al control territorial. Tesis de grado en la Maestría en Sociología. Cali: Universidad del Valle. Recuperada de: http://bibliotecadigital.univalle.edu.co/bitstream/10893/3805/4/CB-0450141.pdf

El Tiempo (2001). FARC atacaron a Arbeláez. Recuperado de: http://www.eltiempo.com/archivo/documento/MAM-486311

Ejército Nacional. División de Infantería José María Córdoba. (2010). Historia del Batallón de Infantería n. 39 Sumapaz. Recuperado de: http://divicor. org/index.php/casamata/154-batallon-infanteria-no-39-sumapaz

González, José (1992). El estigma de las repúblicas independientes, 1955-1965. Bogotá: Cinep.

Halbwachs, Maurice (2004). Memoria colectiva. España: Prensas Universitarias de Zaragoza. 
Jelin, Elizabeth (2002). Los trabajos de la memoria. Madrid, España: Editorial Siglo XXI.

Londoño, Rocío (2014). Juan de la Cruz Varela: sociedad y política en la región de Sumapaz (1902-1984). Bogotá: Universidad Nacional de Colombia.

Marulanda, Elsy (1991). Colonización y conflicto. Las lecciones del Sumapaz. Bogotá: TME-IEPRI.

Molano, Frank (2009). Reflexiones metodológicas de segundo orden en la reconstrucción colectiva de las memorias de las víctimas de crímenes de Estado. En: Serna, Adrián (comp.), Memorias en crisoles. Propuestas teóricas, metodológicas y estratégicas para los estudios de la memoria. Bogotá: Universidad Distrital Francisco José de Caldas.

Noche y Niebla (2001). Informe trimestral enero-marzo de 2001. Boletín $n .^{\circ}$ 20. Bogotá. Recuperado de: http://www.nocheyniebla.org/wp-content/ uploads/u1/19/Niebla19.pdf

Peña, Carina (1997). La guerrilla resiste muchas miradas. El crecimiento de las FARC en los municipios cercanos a Bogotá: el caso del Frente 22. Análisis político, 32 (sept/dic). Bogotá: Universidad Nacional de Colombia.

Pecaut, Daniel (2008). Las FARC. ¿Guerrilla sin fin o sin fines? Bogotá. Editorial Norma.

Pizarro, Eduardo (2011). Las FARC (1949-2011): de guerrilla campesina a máquina de guerra. Bogotá: Editorial Norma.

Semana (2000). Gran ofensiva. Recuperado de: http://www.semana.com/nacion/articulo/gran-ofensiva/43783-3

Ugarriza, Juan y Pabón, Nathalie (2017). Militares y guerrillas. La memoria histórica del conflicto armado en Colombia desde los archivos militares. Bogotá: Universidad del Rosario.

Unesco (2011). Educación y los conflictos armados: la espiral mortífera. En: Informe de Seguimiento de la Educación para todos (EPT) en el mundo. París, Francia: Organización de las Naciones Unidas para la Educación, la Ciencia y la Cultura.

Valencia, Freddy (2010). Paramilitarismo en Cundinamarca y Bogotá. Tesis de pregrado. Recuperada de: http://repository.pedagogica.edu.co/handle/20.500.12209/29 


\section{Entrevistas}

Ausique, Stella (2018). Memorias del conflicto en corregimiento suroriental. David Tinjacá y Wilmer Usaquén (entrevistadores). Archivo personal, 5 de marzo.

Baquero de Pachón, Dora (2017). Memorias del conflicto en corregimiento suroriental. David Tinjacá y Wilmer Usaquén (entrevistadores). Archivo personal, 10 de septiembre.

Beltrán, María del Carmen (2017). Memorias del conflicto en corregimiento suroriental David Tinjacá y Wilmer Usaquén (entrevistadores). Archivo personal, 3 de octubre.

Cubillos, Ernesto (2018). Memorias del conflicto en corregimiento suroriental. David Tinjacá y Wilmer Usaquén (entrevistadores). Archivo personal, $1 .^{\circ}$ de marzo.

Flórez, Edilsa (2018). Memorias del conflicto en corregimiento suroriental. David Tinjacá y Wilmer Usaquén (entrevistadores). Archivo personal, 25 de enero.

Lombana, Iván (2018). Memorias del conflicto en corregimiento suroriental. David Tinjacá y Wilmer Usaquén (entrevistadores). Archivo personal, 14 de marzo.

Mora, Alfonso (2018). Memorias del conflicto en corregimiento suroriental. David Tinjacá y Wilmer Usaquén (entrevistadores). Archivo personal, 5 de enero.

Mora, Telmo (2017). Memorias del conflicto en corregimiento suroriental. David Tinjacá y Wilmer Usaquén (entrevistadores). Archivo personal, 23 de noviembre.

Munarriz, Jairo (2017). Memorias del conflicto en corregimiento suroriental. David Tinjacá y Wilmer Usaquén (entrevistadores). Archivo personal, 19 de octubre.

Ovalle, Gladys (2018). Memorias del conflicto en corregimiento suroriental. David Tinjacá y Wilmer Usaquén (entrevistadores). Archivo personal, 20 de febrero. 
Pachón, Alcira (2018). Memorias del conflicto en corregimiento suroriental. David Tinjacá y Wilmer Usaquén (entrevistadores). Archivo personal, 1. ${ }^{\circ}$ de febrero.

Rodríguez, Adolfo (2018). Memorias del conflicto en corregimiento suroriental. David Tinjacá y Wilmer Usaquén (entrevistadores). Archivo personal, 5 de marzo.

Rodríguez, Julio (2017). Memorias del conflicto en corregimiento suroriental. David Tinjacá y Wilmer Usaquén (entrevistadores). Archivo personal, 15 septiembre. 